\title{
Micro Talk Systems
}

Gary J. Brunswick, Northern Michigan University, USA Brian Gnauck, Northern Michigan University, USA

Raymond Amtmann, Northern Michigan University, USA Samuel P. Graci, Northern Michigan University, USA

\begin{abstract}
This case focuses on a unique and often overlooked product market - sporting event timing systems and supplies - and involves a Japanese manufacturer of radio frequency identification (RFID)-based timing systems called Micro Talk Systems or MTS. Some of the challenges facing MTS, as they begin to penetrate the U.S. timing market, include identifying the size and scope of the timing market, which market segment(s) should MTS focus on, what is the competitive advantage(s) MTS holds compared to other timing systems being marketed in the U.S., and which channel(s) of distribution would prove to be the most efficient and cost effective to use.
\end{abstract}

Keywords: Timing Systems; International Marketing; Channels of Distribution; Market Segmentation

\section{INTRODUCTION}

$\varnothing$

ohn Matter and his son Eric had started their business in the spring of 2009. Superior Timing LLC was designed to apply modern technology to the art and craft of timing races. By 2011, the Matters expertise was in high demand providing timing services to a variety of events, including bike races, skiing, marathons, running races, triathlons, cross country skiing, and swimming.

Micro Talk Systems (MTS) of Tokyo, Japan, had developed one of the best timing systems using RFID (radio frequency identification) for these types of races. It was accurate, versatile, and not too difficult to use. Plus, it was available for a reasonable price tag. Matter and his son, Eric, investigated the system (J-Chip RFID Timing System) and concluded it was the best for their needs.

In early summer of 2009, John Matter contacted the national distributor located on the west coast, J-Chip USA, and made a purchase of the system. The distributor wanted full payment up front, but John Matter suggested half payment up front and the rest to be paid upon delivery. The transaction was completed and the timing system delivered.

John and Eric's business boomed and they found that by the spring of 2011 they needed more equipment (another timing point - a $\$ 12,000$ item). John had contacted the west coast distributor with the intent of placing an order. However, in the interim, he found out the distributor was trying to declare bankruptcy. Consequently, John contacted several other timing companies using the J-Chip technology and discovered that they had difficulty dealing with the west coast distributor which had resulted in financial losses. An internet search revealed that the bankruptcy judge had denied the west coast distributor protection under the bankruptcy laws.

The Matters quickly approached Micro Talk Systems in Tokyo and asked if they could purchase the item directly from MTS. The company agreed, indicating there were a number of problems with the west coast distributor. In fact, the distributor owed MTS about a quarter million dollars for a variety of equipment. The obligation had been accumulating for several years.

Mike Hirashima, Overseas General Manager for Micro Talk Systems Corporation, realized that he faced a dilemma with their U.S. west coast distributor. He had to service Micro Talk Systems' customers and had an unreliable distributor representing the company who owed a large sum of money that would likely go uncollected. He needed good information and a greater understanding of the US market for the J-Chip sports timing system, as well as a strategy to distribute and grow a loyal customer base. 
Early in 2011, Mr. Hiroshima, at the direction of MTS president, Junichiro Hashimoti, made a trip to the US to visit with several US J-Chip timers. He wanted to get a better idea about how to distribute his product and the market for the J-Chip system in the US. He discussed with the timing companies the challenges he faced and possible solutions for increasing J-Chip's share of the RFID timing market.

Mr. Hashimoto was very proud of the timing system his company had developed. He believed in its potential, understood its' capabilities, and was committed to expanding J-Chip's market share of the RFID timing market.

\section{DISTRIBUTION SYSTEM 2012}

Given the difficulty with the national distributor on the west coast, Micro Talk Systems decided to change their distribution plan. Mike Hirashima designed a system of three regional agents with exclusive territories (see Exhibit 1): Mr. Mike Nusbaum's Paceracing Company had the northeast and south regions, John Matter and his son of Superior Timing had the Midwest region, and Mr. Mark Bokman's Racerite had the western region.

Exhibit 1: The Agent Geographic Distribution System For Micro Talk Systems (2011) With Primary Timing Market Highlighted

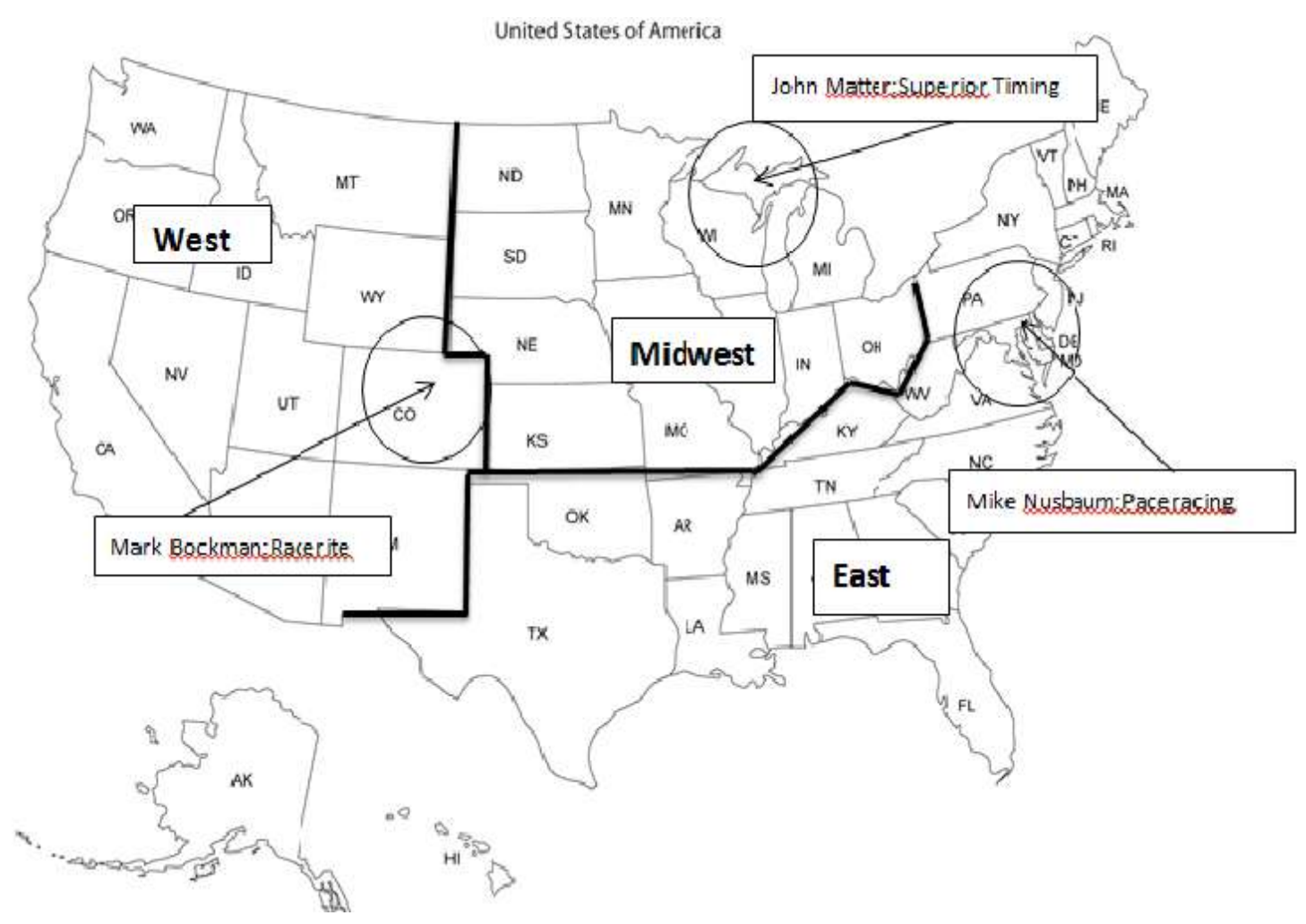

All three of these companies were in the timing business. The role of timing equipment agent for Micro Talk Systems was subordinate to timing races for these companies.

If approached, they were very willing to demonstrate how the equipment worked and sell a system to a potential buyer. However, margins on the system were not large. Micro Talk Systems paid an agency fee once the final payment was made. If a buyer, for example, purchased a $\$ 10,000$ item, MTS paid the agent $\$ 2,000$.

Another problem existed with the current timing distribution system. Buyers for timing equipment of Micro Talk Systems were potential local competitors to each of the three distributors within their exclusive 
territories. For the most part, timing was a local business. Once you got about 200 miles away from your home base, it usually did not make financial sense to bid on timing business. The overhead (travel, motels, food, etc.) costs became too large. An exception to this was very big races where that overhead could be somewhat absorbed. Thus, within their geographic area - a distance of about 200 miles from their home base - they were potential competitors to their customers. Outside that 200 mile base, however, "the buyer-competitor" concept became far less of an issue. However, there was little incentive to market outside the 200-mile radius.

While Mike Hiroshima had instituted the above distribution arrangement, he knew it was not optimal. He felt it was the most cost effective arrangement that could be implemented in a short time frame.

Other possible options included:

1. A hybrid of the above where MTS would supply a sales or marketing rep per region to help promote the company's products in the three territories

2. Identify a national wholesaler or retailer who had a national presence and who could add this product line to an existing array of goods and promote the product

3. Use of e-commerce to promote traffic to the website selling J-Chip products. In this case, the company would provide fulfillment and support services from a national service center.

4. $\quad$ MTS could decide to invest in a corporate sales force to cover the nation.

5. MTS could provide a franchise option as a way of distributing the product.

Mike knew each of these ideas had pros and cons and needed further consideration. At the moment, he was more concerned with getting the system of three regional agents with exclusive territory in place.

\section{MICRO TALK SYSTEMS - A COMPANY PROFILE}

Micro Talk Systems was founded in 1994 as a specialized manufacturer of Radio Frequency Identification (RFID) equipment. In addition to sports timing, this equipment was used in many identification and security applications. They classified their equipment into three categories:

1. Category 1 were lock systems for complex housing.

2. $\quad$ Category 2 were lock systems for locker and cashless systems for fitness spas.

3. Category 3 were active RFID tags for sports timing (J-chip) and automatic movement and traffic controls (S-chip). The RFID equipment for Categories 1 and 2 were produced by Texas Instruments and Micro Talk Systems Corporation produced the Category 3 equipment.

Micro Talk Systems was currently selling their products in Europe, Asia, and the United States. They anticipated an expansion into the South American market and further expansion in the Asian market. J-chip looked for expansion and specialization into the Triathlon and Adventure race markets as they believed their equipment was better than any competing product for this application.

They entered the United States market by attending the New York City Marathon Expo in November 2004. Their operations began in Europe in October 2004 by attending an exhibition supported by the Tokyo Metropolitan Government in Milano, Italy. They expanded into Asia in November 2007 by supporting the hill climb race at Yangmingshan in Taiwan. They had six US Timing companies utilizing their equipment.

Outside of their home country - Japan - MTS realized its largest revenue generation in Europe. They were actively trying to increase their presence and revenue share in the United States market. They were a relatively small company with total capital of approximately ten million and revenues J-Chip revenues averaging $\$ 2,000,000$. 


\section{THE EVOLUTION OF RFID TIMING ${ }^{1}$}

The 100th running of the Boston Marathon in 1996 launched a timing revolution in the U.S. which continues to evolve to this day. A group from Holland developed the ChampionChip system in the early 1990s as the first transponder-based timing system for road races, which made its' debut at Boston. Basically, a transponder or "chip" was attached to the shoelace and when passed over an energized mat, a unique code was transmitted to a decoder box which time stamped the passing and transferred the data to a computer for processing.

ChampionChip virtually owned the U.S marketplace for about the next ten years. U.S. distribution rights were purchased in 1996 and the US distributor sold systems over the next decade to U.S. timers, who wrote checks for \$25,000-30,000 to buy in, and then also paid rental fees for each chip used. The system greatly improved the efficiency of timing and scoring over the manual "pulltag" system, and it introduced the concept of net times, which freed back-of-the pack runners from the tyranny of losing time waiting to start. The ChampionChip system had its share of inconveniences; however, the timing mats were heavy, the chips were expensive and had to be collected, and the read rates were less than $100 \%$.

Now its dominant position had been challenged by a number of competitors. The first fissures in ChampionChip's near-monopoly appeared around 2000 when two companies - AMB-IT and Winning Time - set up U.S. operations. It was tough to sell the new systems, however, because so many timers made large initial investments in ChampionChip equipment. Over the last five years, a second wave of companies introduced new brands that directly addressed the major shortcomings of ChampionChip. IPICO Sports offered a truly portable finish line mat system, allowed system owners to purchase instead of rent the chips, and set a sharply reduced price. ChronoTrack Systems, developed by David Simms offered the first low priced disposable chip, long considered to be the Holy Grail for the next generation of transponder systems. Both companies had shaky starts. IPICO's first high profile event was the 2007 Bolder Boulder 10K, where no results were available until three days after the event. ChronoTrack Systems failed to record massive numbers of finishers at the rainy 2007 Honolulu Marathon, prompting the angry race director to piece together times from the participant photographer's finish line photos and to threaten a lawsuit. Both companies recovered from these mishaps in 2008; however, ChronoTrack successfully timed 17,000 finishers at the Los Angeles Marathon and IPICO streamed results of 40,000 finishers practically instantaneously on to the internet at the 2008 Bolder Boulder 10K. Suddenly, chip timing technology was "in play" and the leaders of the new-kids-on-the-block appeared to be IPICO and ChronoTrack.

J-Chip management was well aware of the emerging technology and the trend toward disposable systems offered by ChronoTrack. Several other US firms had entered the "disposable" chip timing market, including "Jaguar Timing Systems", "Orbit Timing", and an Australian firm called "AccuChip." J-Chip was the dominant system used by timers in Japan (60\% market share) but their market share was being threatened in the running and marathon market. This past year the Tokyo Marathon was being timed with IPICO technology. J-Chip realized that the running and marathon market may not be their primary market given the evolving disposable technology, but they believe their technology was far superior for timing triathlons, adventure/mud run races, and bicycle races. Each system had advantages and disadvantages and their challenge was to find a place for an affordable active chip.

\section{UNDERSTANDING THE TECHNOLOGY}

Two types of transponder timing systems existed - active and passive. An active transponder consisted of a battery-powered transceiver connected to the athlete that emitted its unique code when it was interrogated. Active transponders were considerably more expensive and accurate than passive systems. Active transponders could cost $\$ 100$ each, but they were capable of timing running events, triathlons, road bike races, as well as cross country ski races. Active systems were often thought of as the "gold standard" in the chip timing industry because of their flexibility and accuracy.

A passive transponder did not contain a power source inside the transponder. Instead, the transponder captured electromagnetic energy produced by a nearby exciter and utilized that energy to emit its unique code.

\footnotetext{
${ }^{1}$ Road Race Management, June 2008, titled: Transponder Timing Transformations by Claudia Piepenburg and Phil Stewart 314 Copyright by author(s) $\underline{\text { Creative Commons License CC-BY }} 2013$ The Clute Institute
} 
Passive systems were most effective for running races. These systems had a detection rate of $97 \%$ to $99 \%$. Any misread chips caused results and award winners to be in error. A detection rate of $100 \%$ was highly desirable. Several companies had recently developed a passive "disposable chip" at a cost of about $\$ 2$ per chip. Race directors of large races often liked disposable chip systems because they did not have to recover chips at the finish line, which reduced the need for large numbers of volunteers. Passive systems had less than 100 percent read rate accuracy, especially when significant speed was involved or there was significant racer density (i.e., numerous racers crossing the finish line at about the same time). Some passive systems had detection failure if they became wet or were not placed exactly as directed by the manufacturer.

In both active and passive systems, antennae were placed at the start, the finish, and, in some cases, at intermediate points and were connected to a decoder. This decoder identified the unique transponder code and calculated the exact time the transponder passed a timing point. No one perfect chip system seemed to exist. Exhibit 2 summarizes the basic differences between the two types of systems.

Exhibit 2: Characteristics Of Active And Passive Timing Systems

\begin{tabular}{|l|l|l|}
\hline & \multicolumn{1}{|c|}{ Active System } & \multicolumn{1}{|c|}{ Passive System } \\
\hline Cost & $\$ 18-\$ 80$ per chip & $\$ 1-\$ 12$ per chip \\
\hline Disposable & No & Yes \\
\hline Flexibility & High & Limited \\
\hline Battery Powered & Yes & No \\
\hline Read Height & 6 meters & $<1 \mathrm{~meter}$ \\
\hline Capture Speed & Up to 50 mph & Running, Triathlon \\
\hline Best Suited for: & $\begin{array}{l}\text { Running, Triathlon, Swimming, } \\
\text { Road \& Mountain Biking, } \\
\text { Cross Country \& Downhill Skiing }\end{array}$ & \\
\hline Detection Rate & Near 100\% & $97 \%-99 \%$ \\
\hline Operating Conditions & $\begin{array}{l}\text { All Weather and Wet Conditions, } \\
\text { Can be located higher on body }\end{array}$ & $\begin{array}{l}\text { Wet conditions can cause problems, } \\
\text { Usually located only on ankle }\end{array}$ \\
\hline
\end{tabular}

\section{THE ECONOMY}

The Great Depression of 2007-09 was technically long over at the end of 2011, but recovery was not robust. Seasonally adjusted, 381,000 people filed for unemployment in December of 2011. Even though this was higher than the prior months, the average for this index was at a four-year low. ${ }^{2}$ The economy was picking up, but slowly. Across the U.S., older workers were having a harder time than younger workers, especially when considering weeks on unemployment. Fifty-five to 64-year olds were spending 56 weeks on unemployment, whereas the typical 25 to 30 -year old was only on the unemployment rolls for 36 weeks.

Many of the races that were timed by the J-Chip System catered to younger, rather than older, populations. The recession and slow recovery was somewhat of a positive for J-Chip. According to the Wall Street Journal article entitled: "Fast Times for Jobless Runners", "Americans might be poor, but they certainly aren't slower. ${ }^{3}$ With the economy in the doldrums, more people are discovering that without those 12-hour work days, they are able to pursue fitness goals like never before. Marathons, triathlons, and road races are filling up in record time."

\section{TIMING INDUSTRIES DISPARATE NATURE}

There was no simple way to contact timing organizations to inform them of the J-Chip systems. There were no easily identifiable national timing organizations. There were some regional organizations, such as Southern New England Road Race Officials (SNERRO), with about 30 volunteers who time races, but there were no official race timing organizations trying to serve the many independent timers. There were also running or other sport associations, like the Road Runners Club of America (RRCA), but neither of their websites promotes timing systems

\footnotetext{
2 "Data Suggest Recovery Gaining Steam" WSJ, Ben Casselman,(Friday 30 December 2011)

${ }^{3}$ Albgrotti R. (2009, July 16). Fast Time for Jobless Runners. The Wall Street Journal.
} 
or equipment. There appears to be no training organization for people wanting to get into the timing business, which means there is no company promoting what equipment new entrants should consider using.

Race Measure is a company that provides some online listings for timing companies throughout the world (almost all U.S. companies with the exception of one South African Company). Their main business is course measurement and certification described as follows: "We measure road-race courses for certification, map race courses, and provide race course elevation profiles for running and walking races and events, from one mile road races to Marathon length." A check of their Website - http://www.racemeasure.com - provides a limited list of timing companies. When they did mention chip systems, Micro Talk Systems was not mentioned.

Mike Hiroshima faced some complex distribution issues as 2011 came to an end. Mr. Hashimoto, the president, wanted to see sales expand as he was deeply committed to his timing creation. The next move was Hiroshima's and he had little time to waste.

\section{AUTHOR INFORMATION}

Gary J. Brunswick holds a Ph.D. in Business Administration from Arizona State University, and currently holds the rank of Professor of Marketing at Northern Michigan University. His research interests include marketing strategy, services marketing and e-commerce. His research has been published in range of journals including, Journal of the Academy of Marketing Science, Journal of Consumer Behaviour, The Marketing Management Journal, The Journal of Professional Services Marketing, The International Journal of Case Studies and Research, The Journal of the International Academy of Case Studies, The Academy of Educational Leadership Journal and The Academy of Marketing Studies Journal. E-mail: gbrunsw@nmu.edu

Brian Gnauck is a professor of management at Northern Michigan University. He returned to the classroom in 2000 after serving 15 years as Dean of the Walker L. Cisler College of Business. He has been on the faculty of the college since 1977. Prior to that he was assistant professor of logistic management at the School of Systems \& Logistics at the Air Force Institute of Technology, Wright-Patterson AFB, Ohio. The school offered a master degree in logistics management to U.S. Air Force officers and officers of allied nations of the United States. E-mail: bgnauck@nmu.edu

Mr. Raymond A. Amtmann is an Instructor in the College of Business at Northern Michigan University (NMU). He holds a Bachelor's Degree in Economics from Grove City College and a Master's Degree in Management from Webster University. He was a career officer in the United States Air Force retiring as a Colonel after almost 25 years of service. After his retirement he worked in Business Development, subsequently owning and operating several businesses. In 1999 he began teaching at NMU. At NMU he has taught a variety of subjects including Computer Information Systems, Management Information Systems, Entrepreneurship, and various Management courses. E-mail: ramtmann@nmu.edu

Samuel P. Graci holds a Ph.D. degree from the University of Arkansas and currently holds the rank of professor at Northern Michigan University. He has been on the faculty of NMU since 1982 and has served as Department Head and Interim Dean. His research interests include financial accounting, accounting history and more recently case writing. He has published in a number of journals including The Accounting Historians Journal and Business Case Journal. E-mail: sgraci@nmu.edu (Corresponding author) 


\section{MICRO TALK SYSTEMS - TEACHING NOTES}

\section{CASE DESCRIPTION}

This case primarily focused on the dilemma of a Japanese-based manufacturer of timing systems as they strived to improve and refine their international marketing strategy within the United States. The case focused on several key factors, including the difficulties associated with identifying end users of Micro Talk Systems timing system products in the U.S., branding and product differentiation issues, and exploring options with regard to product distribution. This case has a difficulty level of 2-3 and would be appropriate for sophomore - junior level students. The case is designed to be taught in 2-3 class hours and is expected to require 3-5 hours of outside preparation by students.

\section{RECOMMENDATIONS FOR TEACHING APPROACHES}

This case was designed for use in several different courses, including Marketing Strategy, Marketing Management, International Marketing, and Channels/Logistics. Since students have never heard of the company nor thought about this product category, they should be directed to the company's website immediately upon reading the case (http://mts.greentag.to/). The URL might also cause students to begin thinking about branding, in this case, and product market. The company in question is a small one and therefore students should be able to imagine what it would be like to develop and market a product/system such as this.

The case can be assigned as either an individual or group assignment and the questions provided at the end of the formal case allow for some flexibility in assigning some or all of these questions/issues to students. It might also be advisable to have students prepare a list of questions that they would like to ask Mike Hirashima, should they have the opportunity, and to think about longer-term goals for this company (i.e., what should U.S. sales be in 10 years, etc.).

\section{TEACHING OBJECTIVES}

There are a number of teaching objectives linked to this case, including the following:

1. To expose students to the challenges and opportunities of developing and launching a technology-based brand.

2. To provide students with the opportunity to understand the intricacies of developing a method of identifying and operationalizing a definition of the target market.

3. To challenge students to think about the importance of branding in an international context as well as within the organizational market.

4. To give students the opportunity to explore foreign market entry options and how these impact channel strategy and selection.

\section{POSSIBLE CASE TEACHING QUESTIONS}

1. How can Micro Talk Systems (MTS) efficiently and effectively identify their target market in the U.S.? What is an estimate of the size (in dollars, per year) of the market for event timing systems in the U.S.? Is the market large enough to justify further investment in the U.S.? Might other international markets be more attractive (for entry and/or further development) than the U.S?

Students should readily recognize that there are some inherent problems in not identifying, but measuring, the relative size of the target market in the U.S., given the fragmentation of the market. The market is best understood by individual timers (many of them small part-time entrepreneurs) who provide timing services for various types of sporting events within a fairly limited geographic area (150 - 200 mile radius); there is no national organization that collects data, etc. on individual timers/timing businesses. 
As an exercise, students could try to literally list the specific timed events in their market area (say 50 or 100 miles from campus) and then try to estimate the number of participants in each event. This would allow students to extrapolate these results to a larger unit of analysis (i.e., market size within your state, etc.). A likely conclusion is that the market appears to be large, but may not be large enough to justify even a relatively small investment on the part of MTS; larger geographic areas (with larger events) might be the first priority for a company like MTS.

2. Should MTS consider changing the brand name of their product? Should the same brand name be used internationally? What are the advantages and disadvantages of changing the product/systems brand name at this point in time? What might be some good example brand names for this product/system? How important are brand names in the organizational market?

Students may enjoy focusing on this issue, albeit it may also be of secondary concern given the context of this case. Both MTS and J-Chip do not provide any basis for name recognition outside of the timing industry/community. The core issue is simply how important is the brand name to a product such as this, or are product features/attributes more important? As an exercise, students could be asked to come up with alternative names for the product and/or company and then asked to see if those suggested brand names have already been used/taken by other companies.

3. List, discuss, and analyze the range of competitors of MTS in the U.S.? What is Micro Talk System's competitive advantage and is it meaningful and sustainable?

Students should be asked to prepare a list of "advantages and disadvantages" or "strengths and weaknesses" for each of the major systems described in Exhibit 2. An alternative approach would be to prepare similar lists (+/-) for each of the major timing technology competitors discussed in the case. As a result of these analyses, students should seek to find those timing-related events and instances where J-Chip would be in a dominant position. For example, are there geographic clusters in the U.S. where more of these events may be staged, or are the types of events on the list more or less randomly distributed? Can J-Chip's competitive advantage be summarized into one single statement?

4. List, discuss, and analyze the various options MTS has with regard to their channels of distribution strategy in the U.S.?

This question, more or less, should be at the core of this case, in that in order for MTS to grow as a company in the U.S., it needs to find a coherent and successful distribution strategy. Again, a core problem or challenge in the case is the small size of the market, the fragmentation of the market, and localization of the market - smaller entrepreneurs (via timing businesses) seem to know the most about the end-user and appear to have a geographic stranglehold on event timing in the areas where they provide their services.

One obvious (and possible) distribution solution would be to have a limited number of local/regional event timers provide sales and distribution for J-Chip products. The problems here are: 1) will event timers want to spend time and effort on marketing these products, 2) is it financially worth their time, and 3) will they be essentially selling products to some of their competitors (i.e., competitors in the sense of other event timers who may be timing events in the same markets or those in close geographic proximity). MTS is essentially using this strategy at the current time (the time this case was authored) and is achieving limited results. It is estimated that MTS sells approximately $\$ 2$ million worth of J-Chip products per year. Splitting $\$ 2$ million in sales among 3, 4, or even 10 existing event timers would seem to be asking a lot of these localized timers; again, is the effort worth the possible payoff? It would appear doubtful.

A hybrid of the above-listed distribution option would be for MTS to provide some sales support (i.e., a sales rep or marketing rep) per region who would assist local timers who are now distributing and selling J-Chip products. This might be a good option for MTS to test on a trial basis (say six months or one year) in a more populated geographic area (such as the east coast area of the U.S.). Such an approach would hinge upon the clear establishment of goals for the sales or marketing rep and a clear understanding of how he/she will work with local 
timers in order to effectively market J-Chip's products. Failure to clearly establish goals and coordination among timers is likely to result in various forms of channel conflict.

Another option would be to find an existing wholesaler or retailer who has a national presence and would be willing to take on such a small product line ( $\$ 2$ million per year in sales). The challenge here is really who would be willing to do this - would a national sporting goods retailer (Sports Authority, Dicks Sporting Goods) be interested? Would an existing manufacturer (Wilson, Addidas, Nike) or wholesaler (Maurice Sporting Goods) be interested? Again, the limited size of both the market and the current level of sales for MTS would seem to be limiting factors.

Using an e-commerce-based strategy is another option MTS could pursue. As with any e-commerce-based strategy, the key would be driving traffic to the website. Another key component is to provide timely fulfillment and auxiliary services (i.e., any types of product warranty claims, repairs, etc.). Such an approach may appear to be low-cost initially, but it is also limited in its effectiveness, unless augmented by more traditional investments in forms of advertising, and especially personal selling.

MTS could decide to invest directly in the U.S. and develop a corporately sponsored and controlled sales force and distribution center. Under such a plan, MTS would control all of the marketing and distribution of J-Chip products in the U.S. Such an option would be more of a longer term investment for MTS, where the initial investment may seem irrational in comparison to the sales and profits generated. Over time (five years, for example), the goal of such an approach would be to achieve profitability and to grow sales and market share significantly. Assuming current J-Chip sales in the U.S. are \$2 million per year and the company has a 15\% contribution margin, only $\$ 300 \mathrm{~K}$ in gross profits are generated each year. A direct investment in sales staff and distribution facilities and operations could easily "eat up" $\$ 300 \mathrm{~K}$ (or more) per year.

The key role of pivotal events, such as major races and relevant trade shows, also needs to be recognized almost regardless of which distribution option is pursued. MTS, in conjunction with key members of their channel strategy, would benefit from having a consistent and strong presence at various relevant trade shows and would also benefit from having product placement at major timed events that receive national attention (meaning these are nationally broadcast on cable and/or network networks; for example, seeing the Rolex or Omega brand name at high profile events, such as the Olympics, provides tremendous support to the brand equity for these brands/companies).

One final option that could be considered would be similar to providing franchise opportunities for individuals who would be interested in starting a timing business and then would be supplied with MTS/J-Chip products (i.e., almost like a "timing business in a box"). This would be a more intensive form of distribution from the viewpoint of MTS and would require the development of stronger relationships and maintenance skills on the part of MTS, but on the other hand could results in a network of timers that would be focused on certain types of events, and also timers that would be more loyal to the J-Chip brand.

5. Should MTS consider pursuing other commercial applications of the basic technology currently being used in their timing systems?

This is more of a "big sky" or "big picture" question for students to ponder, given the general nature of the technology at work in J-Chip products. Students could be asked to brainstorm to see what other possible product applications could be thought of for this basic technology and then list the +/- of MTS pursuing opportunities within each of these respective product markets. Certainly the establishment of an MTS corporately owned and operated sales force and distribution center in the U.S. could lead to more easily pursuing other market opportunities for the company beyond the event timing market. 
NOTES 